\title{
Design of control system of Multifunctional Loading and Unloading Equipment
}

\author{
Zhenfeng Zhao ${ }^{1, \mathrm{a}}$, Chuanyun Yi ${ }^{1, \mathrm{~b}}$, Yuansheng Deng ${ }^{2, \mathrm{c}}$ and Leilei Han ${ }^{1, \mathrm{~d}^{*}}$ \\ ${ }^{1}$ Mechanical \& Electronic Engineering Division, WenHua College, Wuhan, Hubei, 430074, China \\ ${ }^{2}$ Sany Automotive Manufacturing Co. LTD, ChangSha, Hunan, 410005, China
}

\begin{abstract}
The main structure of the multifunctional loading and unloading machine is analyzed and designed, including feeding conveyor, intermediate conveyor and unloading conveyor. According to the action of each part of the hydraulic system and electrical system design, in order to meet the needs of more working conditions, the working mechanism realized the overall slip, telescopic conveyor lifting, rotating, telescopic; Combined with the convenience of worker operation, three control modes of remote control, workbench control and terminal control are designed.
\end{abstract}

\section{Overview}

In order to facilitate the cargo transportation and loading and unloading of logistics enterprises, the loading and unloading of different transport equipment, such as aircraft, ships, cars, trains and other automatic loading and unloading machinery has become the mainstream at this stage. As shown in Figure 1, the multifunctional loading and unloading machine is composed of a feeding conveyor, an intermediate conveyor and an unloading conveyor. The conveyor is arranged as a ladder, and the goods are transported in one direction. Feeding conveyor and unloading conveyor structure similar to that of support by

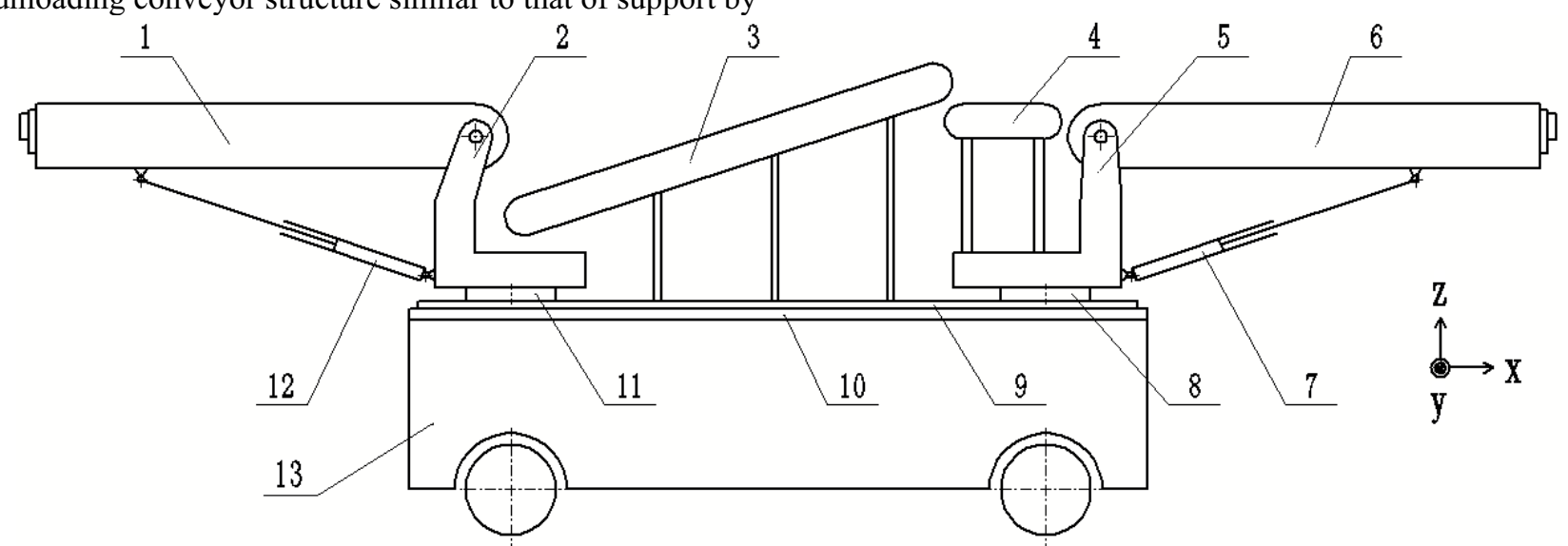

1, 6- Telescopic conveyor, 2- feeding conveyor support, 3- intermediate conveyor, 4- transition conveyor,

5- unloading conveyor support, 7- unloading lifting oil cylinder, 8- unloading conveyor rotary support,

9- slip bracket, 10- chassis auxiliary beam, 11-feeding conveyor rotary support, 12- feeding lifting oil cylinder, 10- 13- truck chassis

FIG. 1 Working device of multifunctional loading and unloading equipment telescopic conveyor, conveyor and lifting oil cylinder, both conveyor support through rotary bearing installed on the sliding bracket, can be achieved in plane xoy + $90^{\circ}$ rotation Angle, lifting oil cylinder can make telescopic conveyor around the hinge support plus or minus $15^{\circ}$ lifting Angle, telescopic conveyor can realize the adjustment of the range of $3050 \sim 6100 \mathrm{~mm}$ length. The intermediate conveyor is mounted on the sliding support, while the transition conveyor is mounted on the support of the unloading conveyor. The sliding support is the installation matrix of all working devices and can slide on the supporting roller on the chassis auxiliary beam, with the sliding range of $-1400 \sim+1400 \mathrm{~mm}$.

\footnotetext{
ae-mail: 24659941@qq.com

be-mail: $1197735000 @$ qq.com

ce-mail: 446468818@qq.com

${ }^{*}$ Corresponding author's de-mail: xiaohan0522@163.com
} 


\section{Overall scheme design of control system}

The control system of multifunctional loader mainly includes hydraulic system and electrical system. Loading and unloading machine in addition to the conveyor roller and machine sliding motor driven, other implementation components are all hydraulic drive, including feeding conveyor telescopic, lifting, turning, unloading conveyor telescopic, lifting, rotating, and hydraulic leg telescopic, lifting and so on. Manual control and automatic control can be adopted according to needs. Each executive part of the loading and unloading machine only needs to control its on and off, so it is controlled by switching quantity. Therefore, the traditional relay contactor control system can be used to meet the requirements. The control principle is to control the solenoid valve through the control of the coil power on and off, and then realize the attitude adjustment of the conveyor; The motor can be started and stopped by controlling the contactor power supply. The control system structure block diagram is shown in Figure 2.

Multifunctional mechanical and electrical control system is mainly composed of solenoid valve, remote control, control button, relay and counter. In order to satisfy the convenience and safety of the workers when the loading and unloading machine is working, three control modes shall be configured, namely remote control, conveyor end control and operation table control. During the loading and unloading work, the working mechanism slides as a whole, the upper and the unloading conveyor expand, rise and fall and turn respectively, and the lifting, stopping and emergency stopping of the conveyor are mainly completed by remote control operation, which can also be controlled on the operating table panel, in order to quickly adjust and position the whole machine shape, and the emergency stopping operation of the conveyor.

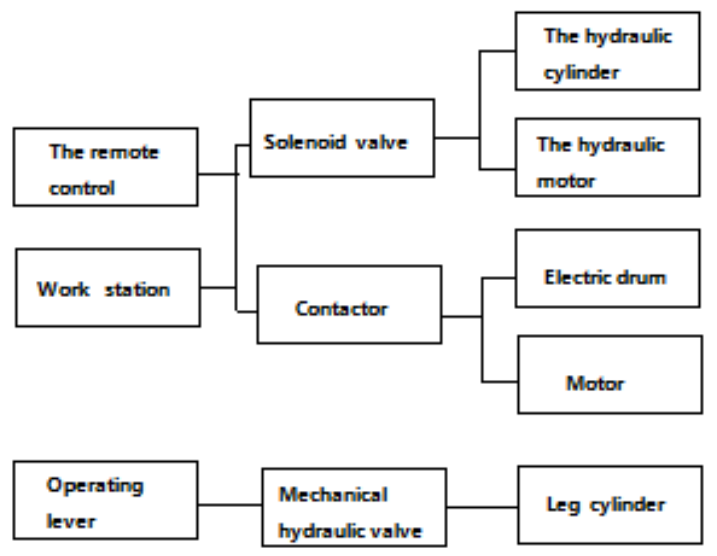

FIG. 2 Structure diagram of control system of multifunctional loader

\section{Hydraulic system design}

The hydraulic system is mainly composed of hydraulic cylinder, hydraulic motor, hydraulic pump, control valve, balance valve, one-way throttle valve, two-way hydraulic lock and other components. hydraulic system of the actuator loop are: feeding conveyor telescopic oil cylinder, lifting oil cylinder feeding conveyor, feeding conveyor rotary motor, discharge conveyor telescopic oil cylinder, unloading conveyor lift cylinder, unloading conveyor rotary motor, front leg left telescopic oil cylinder, front leg right telescopic oil cylinder, back leg left telescopic oil cylinder, back leg right telescopic oil cylinder, front leg lifting oil cylinder, back leg lifting oil cylinder, etc. basic circuit as shown in figure 3 , the hydraulic system is divided into two large loop, adopts double pump drive, figure 3 on the left side of pump 1 drive circuit, the right to pump 2 drive circuit.

In order to ensure the safe and reliable operation of the hydraulic system, other basic circuits must be set in the hydraulic circuit to improve the performance of the hydraulic system:

1) Double one-way throttle valve is set in the rotary motor loop of upper and unloading conveyor to play the role of throttling and regulating speed, and a balance valve, namely a one-way valve parallel relief valve, is set to play the role of buffering and filling oil, especially when the left and right quick reversal.

2) Two-way hydraulic locks are set in the vertical cylinder loops of the four legs and the telescopic and lifting cylinder loops of the upper and unloading conveyors to prevent the hydraulic cylinders from sliding down on their own under the action of the loader's weight.

3) The directional valve of the hydraulic system is a three-position six-way multi-way directional valve, with the function of medium unloading. Moreover, the directional valve itself is equipped with overflow valve to control the pressure of the system. The oil inlet of each valve is equipped with one-way valve, which can reduce the impact of the hydraulic actuator on the hydraulic circuit, especially the hydraulic pump. 


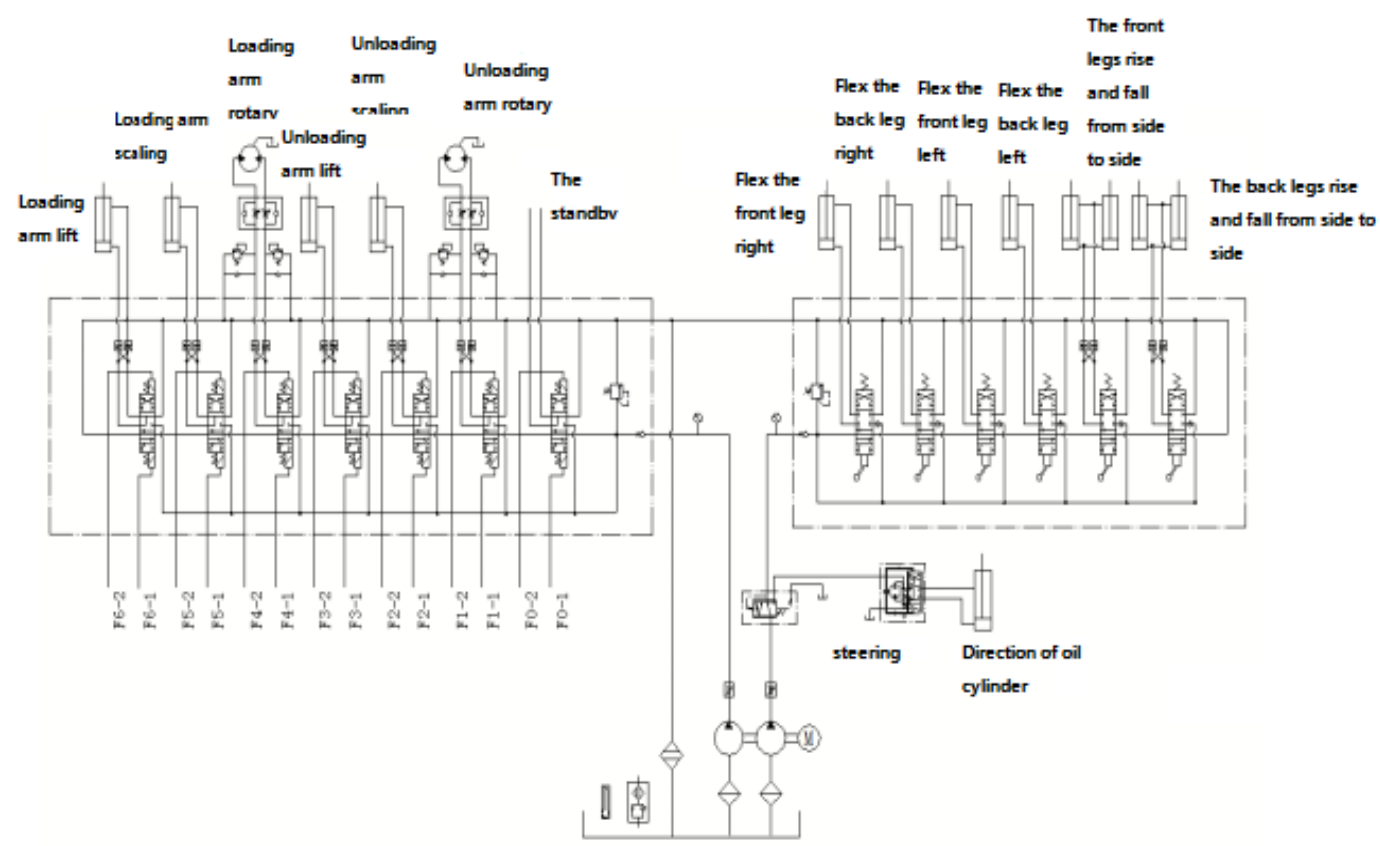

FIG. 3 Schematic diagram of hydraulic system of the loader

\section{Electrical system design}

The electrical system adopts the traditional relaycontactor control mode, which is mainly composed of motor, relay, contactor, switch button, solenoid valve, remote control and other components. The electrical system is divided into two parts: main control circuit and control circuit.

The actuators in the main control circuit include: feeding conveying mechanical and electrical drum, intermediate conveying mechanical and electrical drum, unloading conveying mechanical and electrical drum, hydraulic oil pump driving motor, and slip driving motor. Only the slip motor needs positive and negative rotation, while the other motors only need one-way operation. The main control circuit adopts three-phase $380 \mathrm{~V}$ AC power supply, and can choose the three-phase $380 \mathrm{~V}$ power supply mode of municipal electrician frequency and automobile engine by manual switching. The power supply of the control circuit is dc $24 \mathrm{~V}$, which is converted from $380 \mathrm{~V}$ AC to $24 \mathrm{~V}$ AC first through a $380 \mathrm{~V} \sim 24 \mathrm{~V}$ transformer, then through a rectification circuit, and finally into $24 \mathrm{~V} \mathrm{DC}$. The schematic diagram of the main control circuit is shown in Figure 4 below:

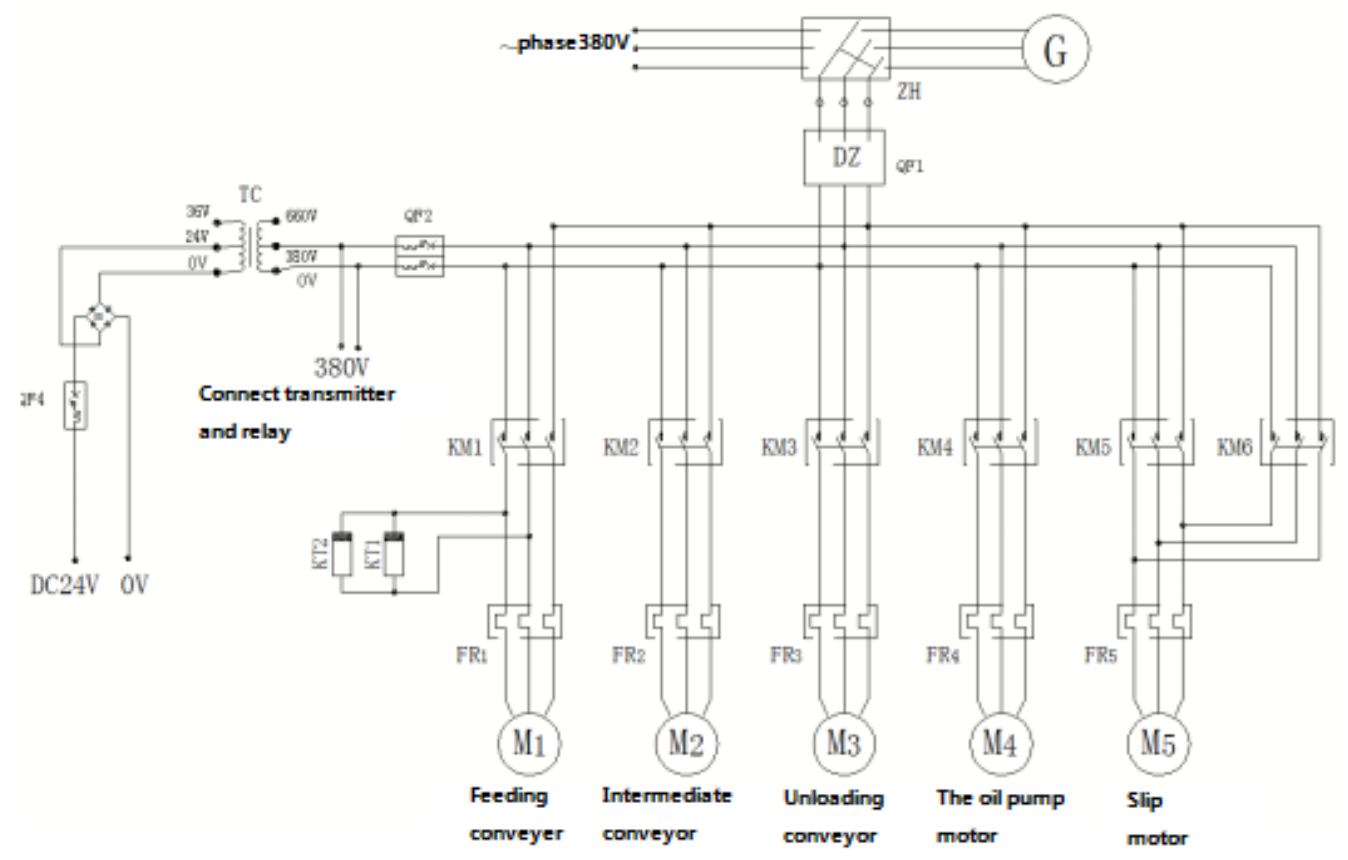

FIG. 4 Schematic diagram of main control circuit 
The control circuit includes an intermediate relay circuit and a button remote control circuit. Figure 5 shows that the power supply is the AC $380 \mathrm{~V}$ intermediate relay circuit. It can be seen from the figure that the loading conveyor mechanical and electrical drum starts first, and then the intermediate conveyor and unloading conveyor start after a period of time. The interval time is determined by the time relay. An interlock circuit is used for the reverse and reverse rotation of the slip motor to avoid short circuit hazard. Thermal relays are installed in the main control circuit of each motor for overload protection.

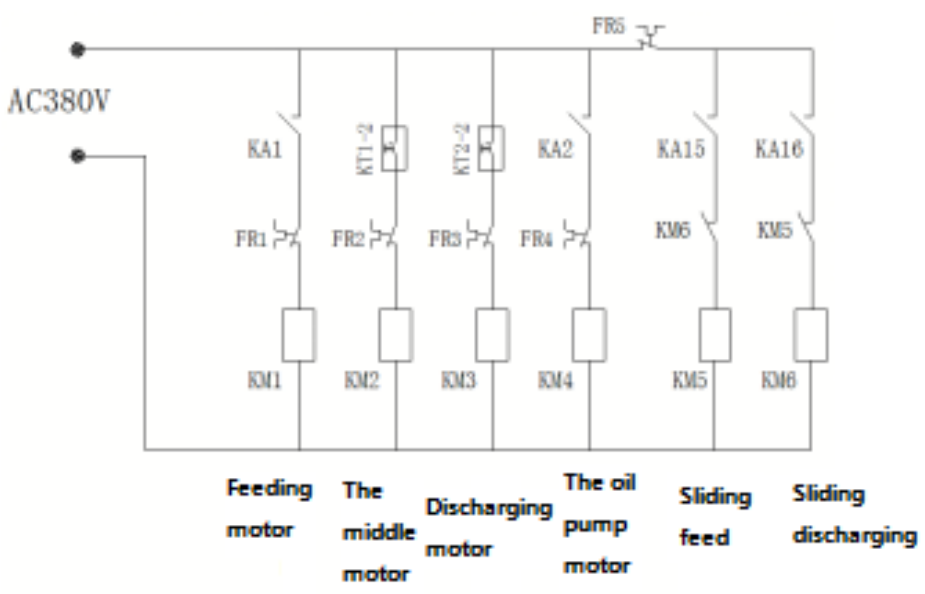

FIG. 5380 V intermediate relay circuit

Figure 6 is the DC $24 \mathrm{~V}$ intermediate relay circuit, where the control object is the coil of all solenoid valves

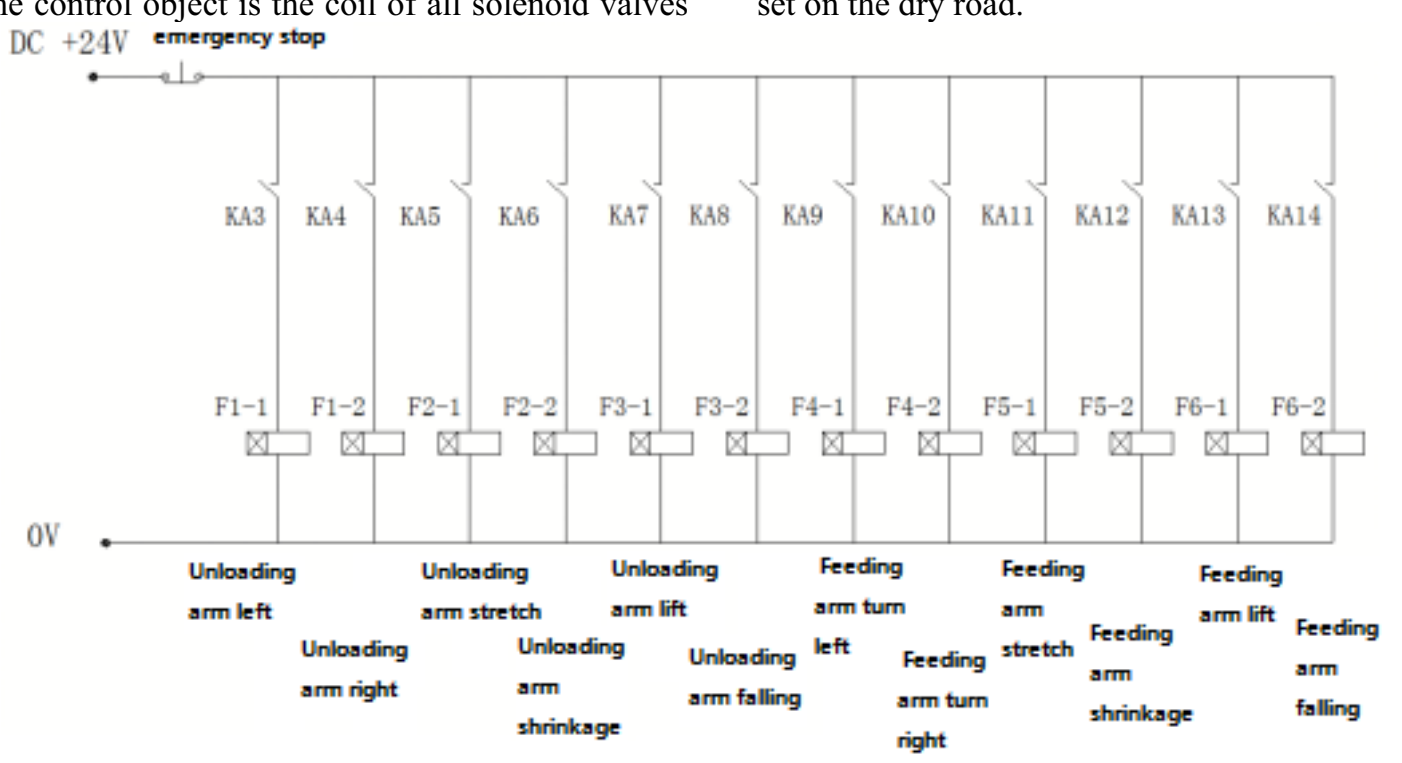

FIG.6 24V intermediate relay circuit

Work station button control circuit as shown in figure 7 , on the keys to achieve control of the loading and unloading machine all functions, through these keys can control all the gestures, loading and unloading machine including the machine slip, feeding conveyor scale, lifting, rotating and unloading conveyor scale, lifting and turning, all of these control the attitude of the loading and unloading machine function inching control buttons all requirements, and can control the conveying machinery roller start-stop and hydraulic pump start stop, and the total power switch. For some possible interference dangerous moving parts adopt trip protection control, including unloading conveyor revolving around limit position trip protection, limit position of feeding conveyor revolving around trip protection, feeding conveyor down stroke protection, discharge conveyor down stroke protection, limit position before and after the sliding body protection. 


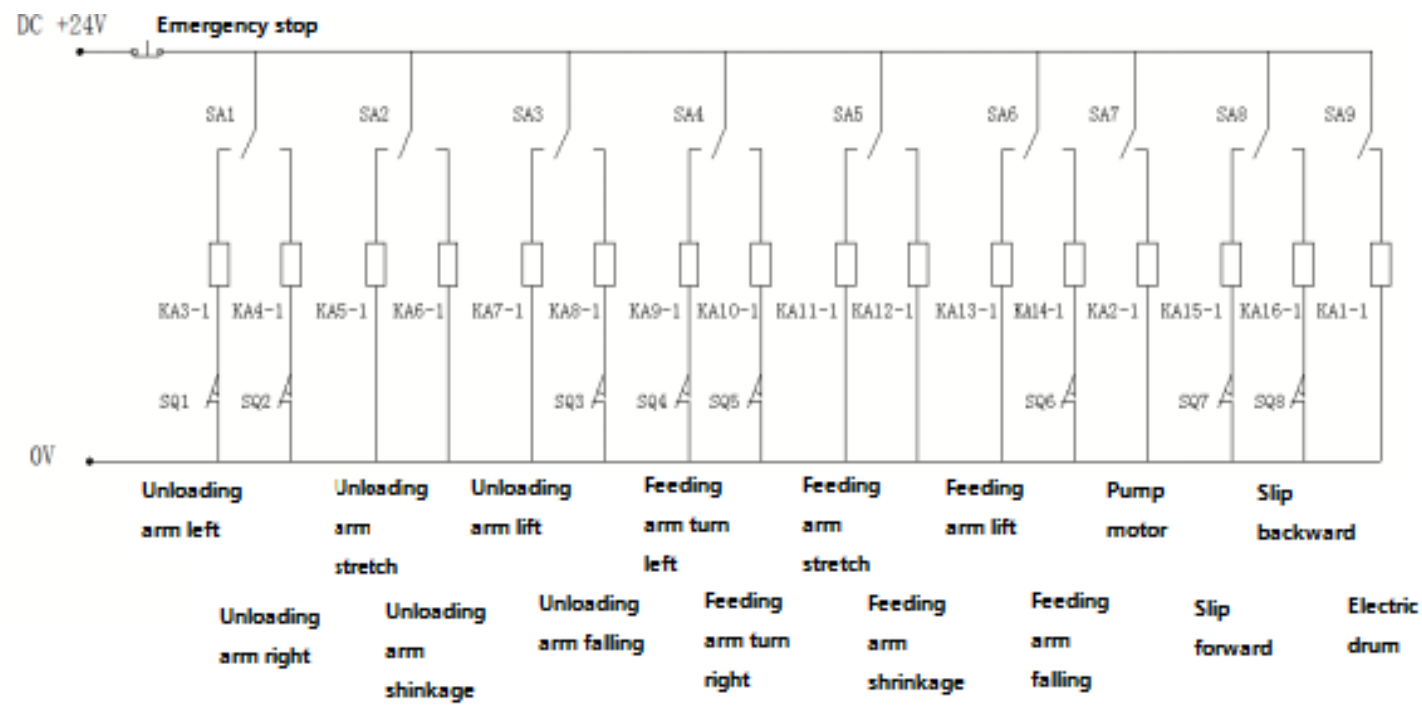

FIG. 7 Schematic diagram of the operation table button circuit

Remote control wiring diagram as shown in figure 8, the remote control is for the convenience of operator in the loading and unloading can be anywhere near the loading and unloading machine according to need to adjust the loading and unloading machine, therefore all remote control does not need to include loading and unloading machine function, only need to realize the function of attitude control, in order to reduce the number of buttons on the remote control, on/discharge conveying mechanism configuration dedicated remote control respectively. The remote control keys of feeding conveyor shall include:

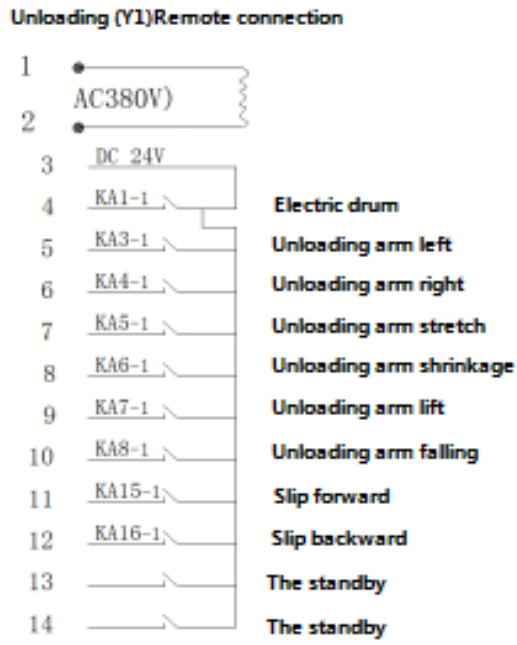

feeding conveyor stretching out, feeding conveyor retracting, feeding conveyor rising, feeding conveyor dropping, feeding conveyor turning left, feeding conveyor turning right, forward sliding, backward sliding, conveyor starting and stopping. The keys of the unloading conveyor shall include: stretching out of the unloading conveyor, retracting of the unloading conveyor, raising of the unloading conveyor, lowering of the unloading conveyor, turning left of the unloading conveyor, turning right of the unloading conveyor, sliding forward and backward, starting and stopping of the unloading conveyor.

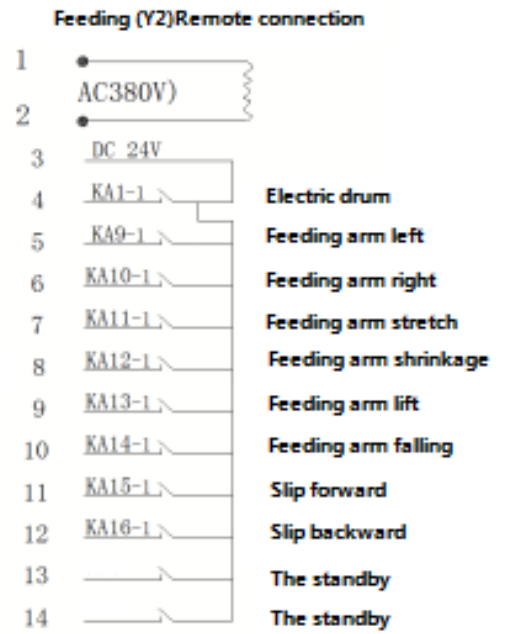

FIG.8 Wiring diagram of remote control

The loading and unloading machine requires that the attitude of the conveyor can also be controlled at the end of the conveyor. Since the conveyor is a telescopic conveyor with complex internal structure, too small space and inconvenient wiring, the terminal control also adopts wireless remote control. The counting system is an independent circuit, which can count the quantity of goods in loading and unloading process and display them in real time. At present, there are mature complete sets of products in the market.

\section{5 conclusion}

This paper studies and designs the control system of the Multifunctional Loading and Unloading Equipment. The proposed design scheme can fulfill the expected functions and technical indexes. However, there are still some areas that need to be improved, such as: lightweight design, expansion of the working scope of equipment and improvement of automation. At present, the process of the 
conveyor into the train carriage is completely manually operated, which requires the coordination of the movement in two directions. Automatic control can be considered for this process in the future.

\section{References}

1. Research of railway Multifunctional loading and unloading machine [J]. Railway Freight, 31(12): 4851

2. He Q, Dong D Q, He Z R, et al. (2010)A New Computer Aided Design System of Belt Conveyor[J]. Advanced Materials Research,905(97): 3667-3670.

3. Bouda T, Bocko P, Hájek T. (2014) Numerical Models of Rubber-Textile Composites of Conveyor Belts[J]. Applied Mechanics and Materials,3602(683): 159164.

4. Guo Yingxun. (2014)Research on key Technologies of electromechanical Control System for belt Steering Loading and unloading [D]. Chang 'an University. 